\title{
10
}

\section{Impacts of Rainfall Data on Model Refinement in Greater Pittsburgh}

\author{
Terry J. Meeneghan, Mark D. Loehlein, Robert E. Dickinson and \\ Timothy Prevost
}

The demand for large-scale watershed and sewershed planning studies in the United States has been increasing steadily over the past ten years. In large part, the demand is driven by major government programs regulating combined sewer overflows, sanitary sewer overflows, and storm water discharges. The implementation of these regulatory programs often results in local or regional public agencies embarking upon large multi-year studies requiring a comprehensive inventory of watershed and sewershed infrastructure, a characterization of the hydrologic and hydraulic function of that infrastructure, and analyses of the water-polluting elements and processes. Significant monetary investments are being made into comprehensive field investigations and surveys, hydrologic and hydraulic models, and regional facilities planning to develop and implement short- and long-term combined sewer overflow (CSO) and sanitary sewer overflow (SSO) control strategies. The amount and rate of rainfall and snowfall are the key driving force in the quantity of extraneous flow that enters public sewers and private service laterals and the frequency and duration of wastewater discharges into receiving water bodies. However, it is not uncommon to observe that disproportionately small investments are being made to improve the precision and accuracy of regional rainfall measurement.

It has been demonstrated and documented in cities throughout the United States and around the world that calibrated radar-rainfall systems can provide accurate and precise rainfall measurement for large geographic areas. However, quantitative evaluations are relatively sparse that document whether

\footnotetext{
Meeneghan, T., M. Loehlein, R.E. Dickinson and T. Prevost. 2003. "Impacts of Rainfall Data on Model Refinement in Greater Pittsburgh." Journal of Water Management Modeling R215-10. doi: 10.14796/JWMM.R215-10.

(C) CHI 2003 www.chijournal.org ISSN: 2292-6062 (Formerly in Practical Modeling of Urban Water Systems. ISBN: 0-9683681-7-4)
} 
enhanced rainfall measurement in fact translates to improved flow simulation performance from hydraulic/hydrologic models. The Saw Mill Run sewershed project at Pittsburgh, Pennsylvania provided a unique opportunity to characterize and quantify the impacts of improved precipitation estimates on the accuracy and reliability of model simulations for storm water runoff, wastewater flow, and $\mathrm{CSO} / \mathrm{SSO}$ volumes. Four alternative rainfall data sources were input into the model and subsequently evaluated:

- the regional long-term record gauge, located at the Pittsburgh International Airport, approximately $12 \mathrm{mi}(19 \mathrm{~km})$ away from the Saw Mill Run sewershed;

- the nearest short- term gauge, located in the Saw Mill Run sewershed;

- a dense network of 5 gauges, located in and around the study sewershed; and

- a calibrated radar-rainfall system, with a pixel resolution of $1 \mathrm{~km}^{2}$.

\subsection{Background Information}

\section{The 3 Rivers Wet Weather Demonstration Program:}

Accurate and reliable precipitation (both rainfall and snowfall) data is needed for the greater Pittsburgh area to support a Regional Long Term Wet Weather Control Plan (RLTWWCP) that is being developed to control CSO and SSO discharges to regional waterways. Preliminary estimates indicate the cost to implement the plan could be as high as US $\$ 3$ billion. There are numerous opportunities to significantly reduce this cost. However, capitalizing on these opportunities is dependant on the ability of hydrologic/hydraulic models to accurately predict complex interrelationships between rainfall, runoff, wastewater flow, and overflow volumes. The Pittsburgh region, under the direction and leadership of the 3 Rivers Wet Weather Demonstration Program (3RWWDP), made the investment to implement a regional radar-rainfall system with the belief that improved precipitation estimates could significantly reduce the ultimate cost of regulatory compliance.

\section{The ALCOSAN Authority:}

The Allegheny County Sanitary Authority (ALCOSAN) serves the City of Pittsburgh and all or part of 82 other municipalities in the region. The Authority provides wastewater conveyance and treatment to a service area of approximately 
$305 \mathrm{mi}^{2}\left(790 \mathrm{~km}^{2}\right)$ and a service population of approximately 939,000 people. ALCOSAN maintains $85 \mathrm{mi}(137 \mathrm{~km})$ of interceptor sewers, which includes both deep tunnel and shallow-cut interceptors, and a 220 million gallon per day (mgd) (830 million liters per day) secondary wastewater treatment plant, which ultimately will be expanded to $875 \mathrm{mgd}$. Along the interceptor system are 317 regulator structures that intercept dry weather flow and control wet weather flow into the ALCOSAN system. ALCOSAN does not have jurisdiction over the collection systems, which are owned and operated by the individual municipalities. The ALCOSAN authority is in the process of refining and implementing a RLTWWCP to control CSO and SSO discharges into area water bodies. It has been estimated that the cost for ALCOSAN and its satellite service communities to implement this plan could be as high as $\$ 3$ billion. Opportunities to reduce this cost are largely dependent upon the refinement of the hydrologic and hydraulic characterization of combined and separate sewer systems within the region, the refinement of the control facilities design process, and municipalities working together.

\section{The Saw Mill Run Study Area:}

The Saw Mill Run watershed is located in the south-central portion of the ALCOSAN service area. The watershed comprises an area of approximately 20 $\mathrm{mi}^{2}\left(52 \mathrm{~km}^{2}\right)$ and contains a service population of approximately 115,000 who reside in 10 municipalities. Approximately $27 \%$ of the service area is served by combined sewers, $54 \%$ is served with separate storm and sanitary sewers, and $19 \%$ of the area is either undeveloped or served by individual on-lot septic systems.

\section{Precipitation Measurement:}

A calibrated radar-rainfall system was implemented in April 2000 to monitor precipitation (rainfall and snowfall) in the greater Pittsburgh region. The system is owned and operated by the 3RWWDP, who made the investment to implement the regional system with the belief that improved precipitation estimates could significantly reduce the ultimate cost for regulatory compliance. The radar-rainfall system utilizes a geo-referenced $1-\mathrm{km}^{2}$ pixel grid, and 872 pixel squares are required to cover the entire ALCOSAN service area. The system is supported by a network of 21 heated precipitation gauges installed at an average density of one gauge per $15 \mathrm{mi}^{2}\left(40 \mathrm{~km}^{2}\right)$. Calibrated radar-rainfall data was "filled" with gauge data to provide a continuous precipitation record that was input into the hydrologic/ hydraulic model. For storms large enough 
to meet specified criteria, radar-based data were used. For smaller storms, gauge data was spatially distributed using the inverse-distance-squared method. The precipitation data is provided to engineers, municipalities, and other interested individuals via an Internet site maintained by 3RWWDP. The initial start-up cost to implement the system was approximately US $\$ 175,000$, which included the gauge equipment, electrical and telephone service connections, installation labor, geo-referencing, and radar customization. The monthly cost to maintain the system is approximately US $\$ 5,500$, which includes phone lines, system maintenance, radar image calibration, data quality reviews, monthly reporting, and web-site maintenance. In the spring of 2003 , the calibrated radarrainfall system and web site will be upgraded to provide "near" real-time and predictive precipitation data. A map showing the ALCOSAN service area, the pixel-grid system, and the locations of the supporting gauges is provided in Figure 10.1.

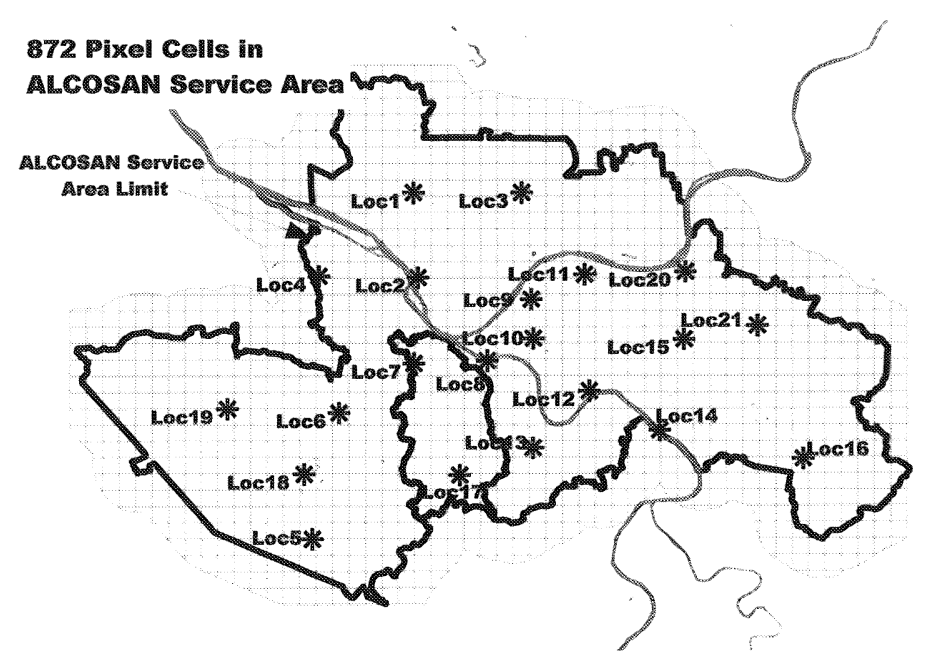

Figure 10.1 NEXRAD pixel grid with supporting gauge sites.

\section{Wastewater Flow Measurement:}

The ability to assess the accuracy of a hydrological/hydraulic model and potential improvements from improved rainfall data depends on the availability of accurate and reliable monitored wastewater flow data. A network of monitors was established to provide the required depth and flow data. Two broad categories of sewer flow monitoring were conducted in support of the model and the Saw Mill Run study: regional monitoring along the ALCOSAN 
interceptor, and sewershed monitoring along municipal trunk sewers near the point of connection with the ALCOSAN system. Continuous regional flow monitoring was conducted at three shallow-cut interceptor sites. Sewershed monitoring was conducted continuously at six separate sewersheds and three combined sewersheds. A total of 96 meter-months of data were collected at the twelve sites and used in the analysis. A map showing the Saw Mill Run study area, monitoring sites, and the corresponding monitored sewersheds is provided in Figure 10.2.

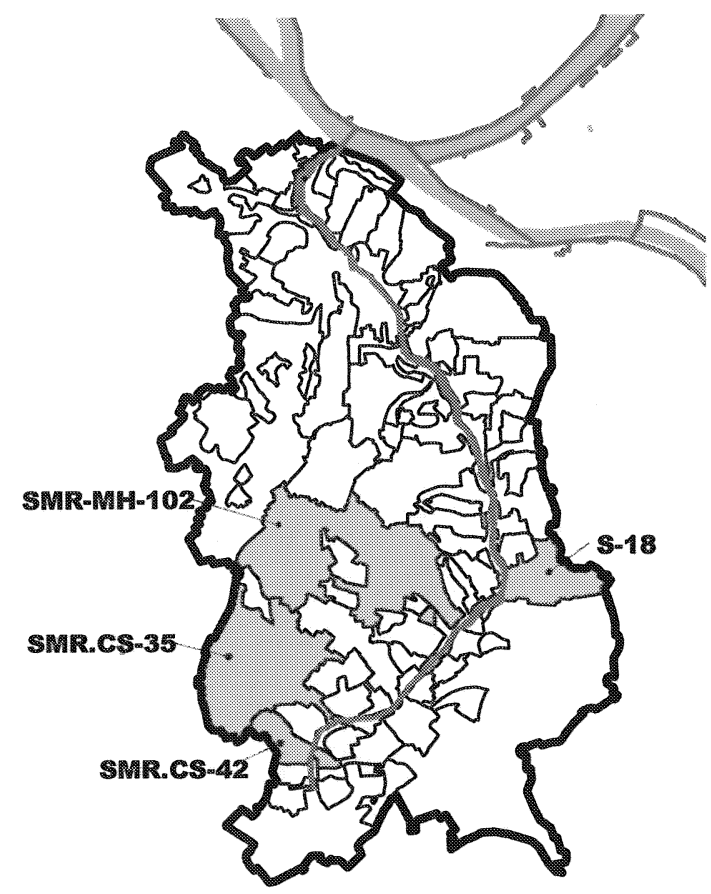

Figure 10.2 Saw Mill Run study basin and monitored sewersheds used for analysis.

\subsection{Alternative Precipitation Data Sources}

Four alternative sources for rainfall data were analyzed and assessed for the Saw Mill Run project. Both rainfall and snowfall data were available and used in the project, but only rainfall is analyzed in this chapter. The alternatives were selected to represent the "typical" range of rainfall sources that are used for sewershed modeling and analyses. 
Long-Term Regional Gauge:

The long-term regional gauge for the Pittsburgh region is located at the Pittsburgh International Airport (PIA), which is approximately $12 \mathrm{mi}(19 \mathrm{~km})$ from the Saw Mill Run sewershed. Hourly digital data are readily available at this gauge. Several sewershed studies have been performed using this data, when no other rainfall data sources were available. Using a single gauge necessitates the assumption of a uniform rainfall distribution over the sewershed area being studied. The relative locations of the regional gauge and the Saw Mill Run sewershed are shown in Figure 10.3.



Figure 10.3 Alternative rainfall data source - regional gauge and nearest gauge.

\section{Nearest Gauge:}

A gauge was installed within the Saw Mill Run sewershed. The heated gauge site provides continuous precipitation data in 5-min increments. Again, the use of a single gauge necessitates the assumption of uniform rainfall over the study area. Many sewershed analyses in the Pittsburgh have been performed with this approach of installing and maintaining a single gauge within the study area to provide needed precipitation data. Figure 10.3 shows the location of the gauge within the Saw Mill Run sewershed. 


\section{Network of Gauges:}

A medium-density network of 5 continuous recording gauges was installed in and around the Saw Mill Run sewershed. These gauges are a part of the regional network of 21 gauges that are used to calibrate the regional radar-rainfall system. The heated gauge sites are synchronized on a weekly basis and provide continuous data in 5-min increments. The gauge network allows the analyst to use the inverse distance squared method to approximate the spatial distribution of rainfall over the study area. Some sewershed analyses in the Pittsburgh region have been performed with this approach of installing several gauges in and around the area of study to provide additional insights into the spatial distribution of precipitation. Figure 10.4 shows the locations of each of the gauges in the network and how the inverse distance method was used to determine spatially varied precipitation values within the Saw Mill run sewershed.

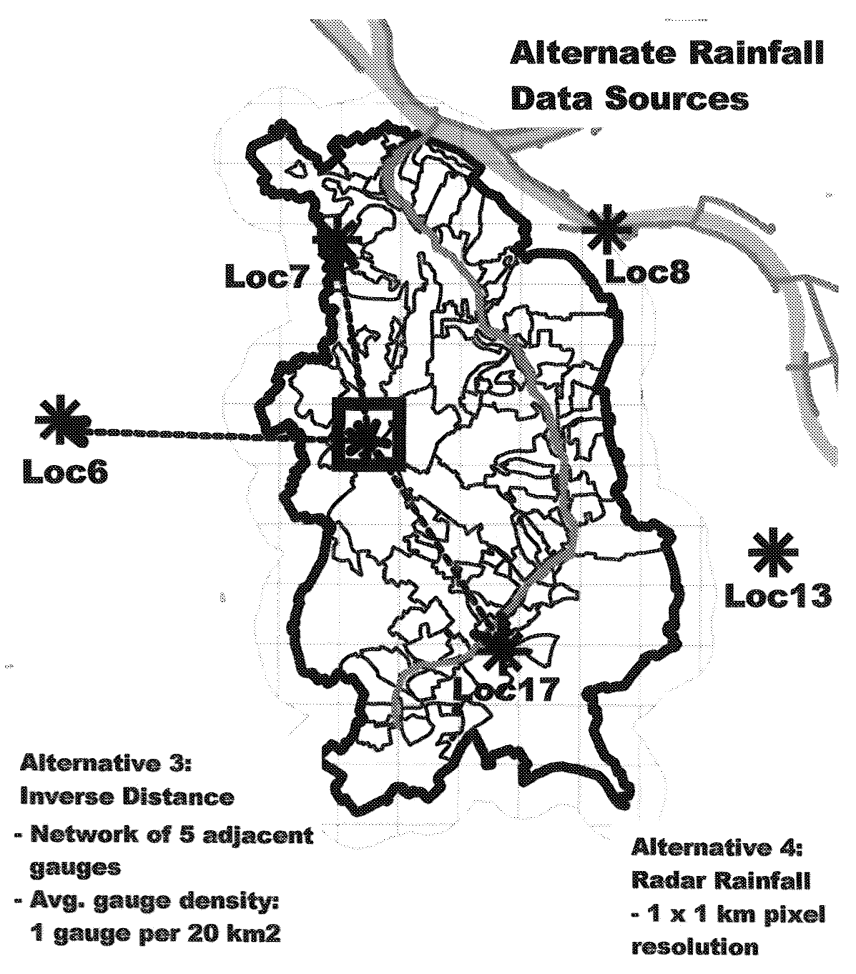

Figure 10.4 Inverse distance-squared gauge weighting. 


\section{Calibrated Radar-Rainfall System:}

For larger storms that meet specific criteria, radar reflectivity data are related to precipitation intensity at a high degree of spatial and temporal detail. Weather radar imagery is calibrated to a network of 21 geo-referenced and synchronized gauges to provide a more precise representation of rainfall through space and time. The grid values are later area-weighted to provide continuous rainfall data for individual sewersheds and sub-sewersheds. Precipitation data (both rain and snow) from the calibrated radar-rainfall system is used by ALCOSAN and the 3RWWDP in support of demonstration projects and the RLTWWCP. A map showing the geo-referenced grid over the Saw Mill run sewershed and the gauge sites used to calibrate the radar images is provided in Figure 10.4.

\subsection{Extraneous Flow Quantification}

Rainfall dependant infiltration and inflow (RDII) was the model variable that was analyzed to quantify the benefits of improved rainfall measurement on hydrologic/hydraulic model simulations. RDII is extraneous flow that is present in sewer systems during and after storms. RDII quantities tend to increase rapidly during a storm, and then dissipate gradually to seasonal base flow levels over the next few days. Ground water infiltration (GWI) is extraneous flow, present during both dry-weather and storm events, that enters a sewer system and/or service lateral connection from the ground through system defects. The accurate quantification of GWI and RDII is important to the development and refinement of the hydrologic/hydraulic models that support the ALCOSAN regional LTWWCP because excessive RDII can limit the net available conveyance capacities in sewers and increase the frequency and duration of sewer back-ups and CSO/SSO discharges. A series of RDII analyses were conducted to quantify and characterize GWI and RDII in monitored portions of the Saw Mill Run study area. The four alternative rainfall datasets described above were input into the RDII analyses in order to quantify and characterize the benefits of improved rainfall measurement on hydrologic model results.

To quantify RDII for each of the four alternative rainfall data sources, a five-step process was used to perform dry-weather and wet-weather flow analyses of the monitored flow data in Saw Mill Run. For the monitoring data available, the analyses were performed using the RDII Utilities Programs. The five-step procedure is listed below and described in the following paragraphs.

1. Flow data preparation,

2. rainfall data preparation, 
3. dry-weather flow evaluations and determination of base flow quantities,

4. hydrograph decomposition to determine RDII quantities, and

5. triangular unit hydrograph curve fitting.

\section{Flow Data Preparation:}

Monitored data was entered into the RDII Utilities Program and reviewed to confirm that it was complete, properly formatted, and compatible with the requirements of the subsequent RDII analysis. The review included error checking, identifying data gaps, and filling in periods of missing data.

\section{Rainfall Data Preparation:}

Data from each of the four alternative rainfall sources were entered and reviewed to confirm that they were complete and met the requirements of the RDII analysis process. To quantify RDII, there must be a corresponding rainfall data point for each wastewater flow data point. The review included error checking and filling in periods of missing data with corresponding data from adjacent gauges.

\section{Dry-Weather Flow Evaluations:}

After the data entry, format conversions, and reviews of the flow and rainfall data had been completed, dry-weather analyses were performed to determine the typical diurnal pattern for the sum of base wastewater flow (BWWF) and GWI. The analyses consisted of identifying days in the record that were not affected by a rainfall event. The methodology also eliminated other atypical days in which the dry-weather flows may have been affected by holidays or other special events. The monitored diurnal patterns for the selected dry-weather days were averaged. Average weekday and weekend dry-weather flow hydrographs were computed and used in subsequent hydrograph decomposition processes to determine the RDII flows during rainfall events.

\section{Hydrograph Decomposition:}

The average daily dry-weather flow (ADDWF) hydrographs calculated by the program were then used to quantify RDII volumes for each of the storms that occurred during the analysis period. The first step in the analysis was to manually adjust GWI rates to account for seasonal variations. The seasonal adjustments were based on the assumption that the difference between monitored flows and the computed ADDWF hydrograph should be approximately 
zero before and after a storm. RDII volumes and peak flows for individual storm events were calculated by subtracting the seasonally adjusted dry-weather flow hydrograph (wastewater plus GWI) from the total monitored flow (wastewater plus GWI plus RDII). The subtraction process is called hydrograph decomposition. An illustrative example of hydrograph decomposition can be seen on Figure 10.5. The top line is the monitored wastewater flow, the total of the BWWF, GWI, and RDII components. The bottom lines are the BWWF and seasonally adjusted GWI components. The second line from the top is the computed RDII hydrograph, calculated by subtracting the BWWF and GWI components from the total monitored wastewater flow. For each monitored storm, the total rainfall volume over the monitored sewershed area, the storminduced RDII volume, and the total $\mathrm{R}$-value were computed. The total $\mathrm{R}$-value is defined as the ratio of the calculated RDII volume to the rainfall volume over the sewered area, expressed as a percent. An R-value of 0.07 indicated that $7 \%$ of the total monitored rainfall volume that fell over the sewershed area made its way into the sewer system as monitored RDII.

This total R-value was the basis of comparison for the four alternative precipitation data sources and the basis for quantifying the benefits of improved rainfall measurement on the performance of hydrologic models. Calculated Rvalues are not constant and vary from storm to storm. The R-value for an individual storm is dependent on several variable factors such as antecedent moisture conditions, rainfall intensity, groundwater levels, and season. Some

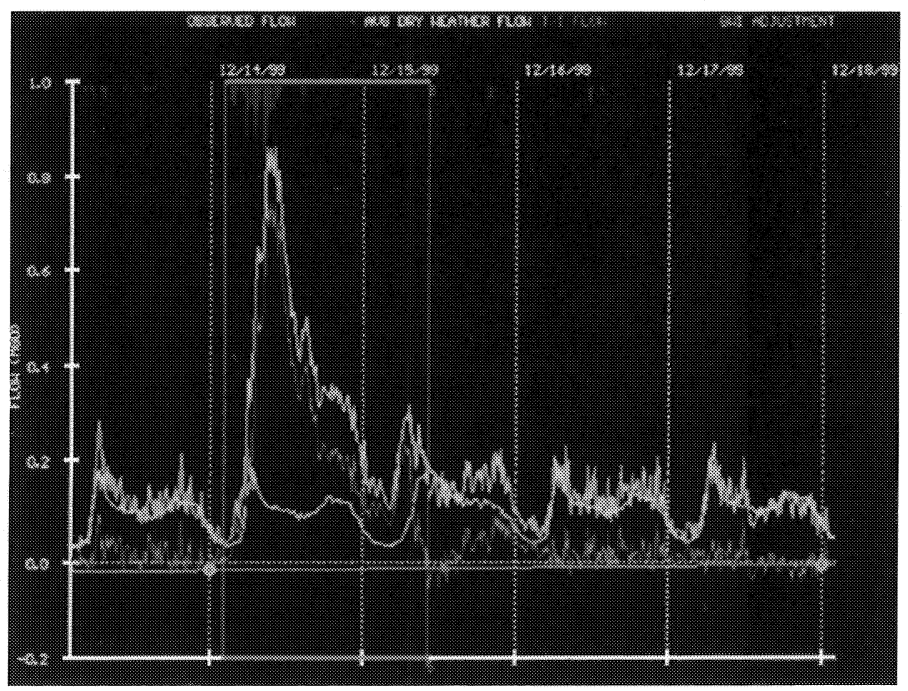

Figure 10.5 Example of hydrograph decomposition. 
of the variability in the computed R-values also is due to non-representative rainfall being used in the RDII quantification analysis because the real rainfall volume over the monitored sewershed was not accurately represented by the gauge data. Since only the rainfall data were varied in the comparisons, any observed differences in the magnitude and variability of computed R-values should be attributable to improved rainfall measurement.

\subsection{Overview of Analysis Results}

As previously described, four alternative rainfall data sources were analyzed and assessed for the Saw Mill Run project. The focus of the analyses was to quantify and characterize how the alternative precipitation data that was input into the model impacted the magnitude and variability of computed total Rvalues from the RDII analyses. The series of analyses were performed to determine how improvements in the spatial distribution and resolution of precipitation input into the model improved the accuracy and precision of model simulation results for the monitored separate sanitary sewered areas in the Saw Mill Run basin.

For example, Figure 10.6 shows the calculated total R-values for each of the monitored events analyzed in the S-18 (Maytide Avenue) sewershed using the regional PIA gauge as the rainfall data source. The vertical bars show the



Figure10.6 RDII analysis results for S-18 sewershed using regional PIA rainfall data. 
calculated total R-values for each of the 25 storm events that were analyzed during the monitoring period using the PIA rainfall data. The horizontal solid line shows that the mean R-value for all the analyzed events was 0.138 , indicating that on average, approximately $13.8 \%$ of the rainfall that fell over the S-18 sewershed made its way into the sanitary sewer system as monitored RDII. The dashed horizontal lines depict the $66 \%$ confidence limits (plus or minus one standard deviation from the mean) of the analysis results. The confidence limits are shown to depict the relative degree of variability, and any confidence limit value could have been used. As the figure shows, the variability in total R-value from storm to storm is quite large, and the total R-values range from 0.012 to 0.264 . As explained earlier, the magnitude and variability of calculated $R$-values is dependant on many factors, including non-representative rainfall over the monitored sewershed.

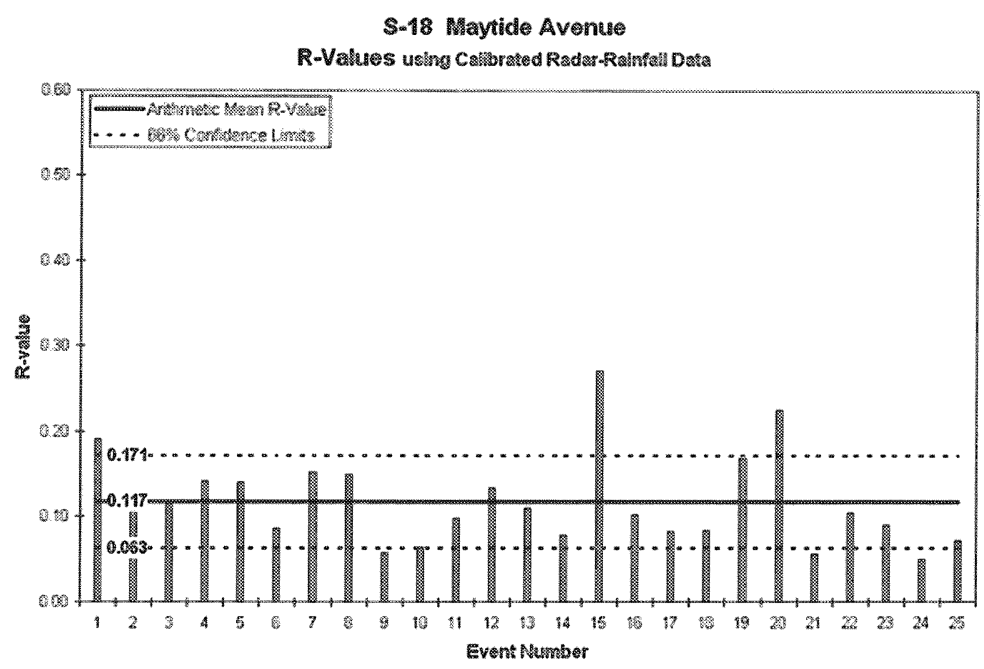

Figure 10.7 RDII analysis results for S-18 sewershed using calibrated radarrainfall data.

The same analysis was conducted in this sewershed (as well as the other monitored sewersheds in Saw Mill Run) using the other 3 alternative data sources for rainfall input. For example, Figure 10.7 shows the total R-values for the same 25 monitored events analyzed in the S-18 (Maytide Avenue) sewershed, this time using calibrated radar-rainfall as the data source. Since only the precipitation data was changed, it can be assumed that any observed differences in the magnitude and variability of the computed R-values should 
be attributed to the increased/decreased resolution and accuracy of monitored rainfall. As the figure shows, the mean R-value for all the events analyzed using the calibrated radar-rainfall data was 0.117 , meaning that, on average, approximately $11.7 \%$ of the rainfall that fell over the S- 18 sewershed made it's way into the sanitary sewer system as monitored RDII. The "leakiness" of the sewer system did not change, so the changes in the magnitude of the mean R-value are attributable to improvements in rainfall measurement. The dashed horizontal lines illustrate the $66 \%$ confidence limits in the analysis results. The figure also shows that the confidence limits, and the corresponding degree of R-value variability from storm to storm, decreased significantly compared to the variability of the R-values computed using the regional PIA gauge data. Only the rainfall data were changed, and the other factors that can account for the magnitude and variability in computed R-values were held constant. Therefore, a comparison of Figures 10.6 and 10.7 should show the impacts of improved rainfall data on the magnitude and variability of the model parameter, RDII.

These same types of comparisons were made for other monitored separate sanitary sewered areas in the Saw Mill Run basin. For each sewershed, RDII analyses were conducted using the calibrated radar-rainfall as the rainfall data source. The resulting R-values based on these analyses were then compared to the R-values computed using the three other alternative precipitation data sources (PIA regional gauge, nearest gauge, IDS weighting of gauges).

Figure 10.8 shows a comparison of how the computed R-values differed using the PIA regional gauge as the precipitation data source compared to using the calibrated radar-rainfall data. The vertical black bars show the percent difference in the calculated mean R-value for each of the four monitored separate sanitary sewersheds analyzed (calculated as the difference between the mean $\mathrm{R}$-values divided by the radar-rainfall value, times $100 \%$ ). The horizontal black dashed line shows the system-wide average percent difference in these R-values. As the figure shows, the system-wide mean R-value, the model representation for the leakiness of the sewer system, decreased by approximately $16 \%$ when comparing the results generated using the calibrated radar-rainfall data to those computed using the PIA regional gauge data. Therefore, more representative rainfall over monitored sewersheds (remembering that the airport gauge is $12 \mathrm{mi}, 19 \mathrm{~km}$, away) improved the model representation of the magnitude of rainfall that enters the sanitary sewer system.

Also depicted on the figure, the vertical gray bars show the percent difference in the calculated standard deviation in the computed R-values for each of the monitored separate sanitary sewersheds analyzed. The horizontal 


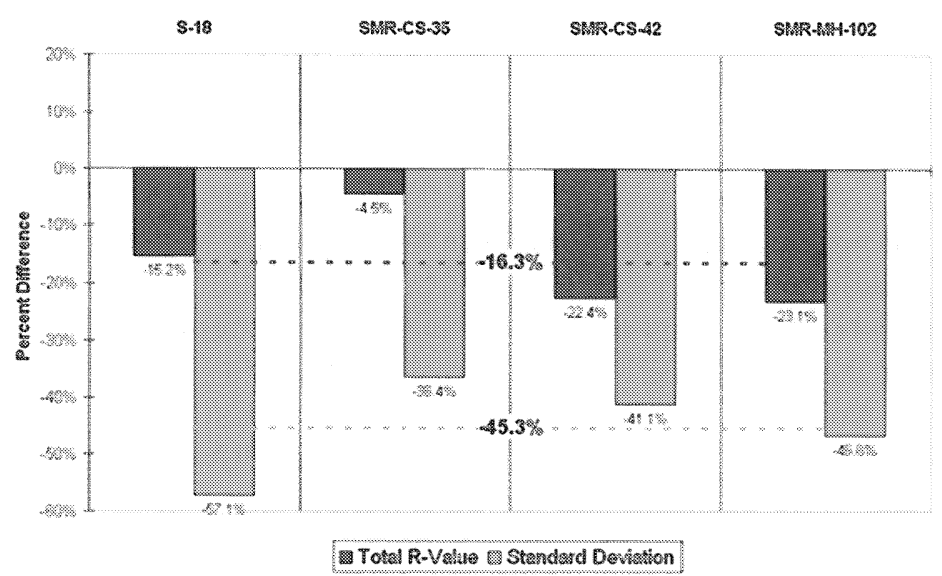

Figure 10.8 R-value comparison: calibrated radar-rainfall vs. regional gauge (PIA).

gray dashed line shows the system-wide average percent difference in this standard deviation. As the figure shows, the system-wide mean standard deviation, or degree of variability, in the R-values decreased by approximately $45 \%$ when comparing the results generated using the calibrated radar-rainfall data to those computed using the PIA regional gauge data. Therefore, more representative rainfall measurement significantly decreased the degree of variability observed in computed R-value from storm to storm. Since only the precipitation values were changed, and not any of the other physical factors that could impact the observed variability, the $45 \%$ improvement is attributable to more representative rainfall measurement.

Figure 10.9 provides a comparison of how the computed $\mathrm{R}$-values differed using the nearest gauge (forcing the modeler to assume a uniform rainfall distribution over the sewershed) as the precipitation data source compared to using the calibrated radar-rainfall data (and a spatially distributed rainfall). The vertical black bars show the percent difference in the calculated mean R-value for each of the four monitored separate sanitary sewersheds analyzed. The horizontal black dashed line shows the system-wide average percent difference in these R-values. As seen on the figure, the magnitude of the system-wide mean R-value decreased by approximately $11 \%$ when comparing the results generated using the calibrated radar-rainfall data to those computed using the data from the nearest gauge ( $\left.R G \_17\right)$. This $11 \%$ difference quantifies the improvement in model representation of total $\mathrm{R}$-values associated with using a spatially varied rainfall distribution over the sewershed instead of using a constant value over the entire sewershed. 




Figure 10.9 R-value comparison: calibrated radar-rainfall vs. nearest gauge.

The vertical gray bars also seen on the figure show the percent difference in the calculated standard deviation or variability in the computed R-values for each of the four monitored separate sanitary sewersheds analyzed. The horizontal gray dashed line shows the system-wide average percent difference in this standard deviation. As the figure shows, the system-wide mean standard deviation in the R-values decreased by a approximately $33 \%$ when comparing the results generated using the calibrated radar-rainfall data to those computed using the nearest gauge (RG_17) data. This $33 \%$ difference should be the approximate magnitude in the improvement in R-value variability associated with using a distributed rainfall versus a constant rainfall over the sewershed.

Finally, Figure 10.10 shows a comparison of how the computed R-values differed using the inverse distance-squared weighting of adjacent gauges as the precipitation data source as compared to using the calibrated radar-rainfall data. Both precipitation measurement alternatives use a spatially distributed rainfall, but the radar-rainfall data has a finer resolution. The lighter colored vertical bars show the percent difference in the calculated mean R-value for each of the monitored separate sanitary sewersheds analyzed. The lighter colored horizontal dashed line shows the system-wide average percent difference in these Rvalues. As shown on the figure, the system-wide mean R-value decreased by approximately $7 \%$ when comparing the results generated using the calibrated radar-rainfall data to those computed using the inverse distance-squared weighting of adjacent gauges. However, improvements were only observed in two of the four monitored sewersheds. No significant difference was observed in one of the sewersheds, and there was an observed detriment in one of the 
sewersheds. This seems to indicate that representative rainfall over the sewershed and a spatially distributed rainfall over the sewershed improves model representations of the magnitude of rainfall that enters sewers as monitored RDII. However, increased resolution in the distribution pattern produced mixed results.

Also depicted in the figure, the darker colored vertical bars show the percent difference in the calculated standard deviation in the computed R-values for each of the monitored separate sanitary sewersheds analyzed. This is an indicator of the variability from storm to storm. The darker colored horizontal dashed line shows the system-wide average percent difference in this standard deviation. As the figure shows, the system-wide mean standard deviation in the $\mathrm{R}$-values decreased by a factor of approximately $10 \%$ when comparing the results generated using the calibrated radar-rainfall data to those computed using the inverse distance-squared weighting of adjacent gauges. Improved rainfall distribution resolution improved the variability in $\mathrm{R}$-value from storm to storm in some sewersheds, but in others the variability actually increased.

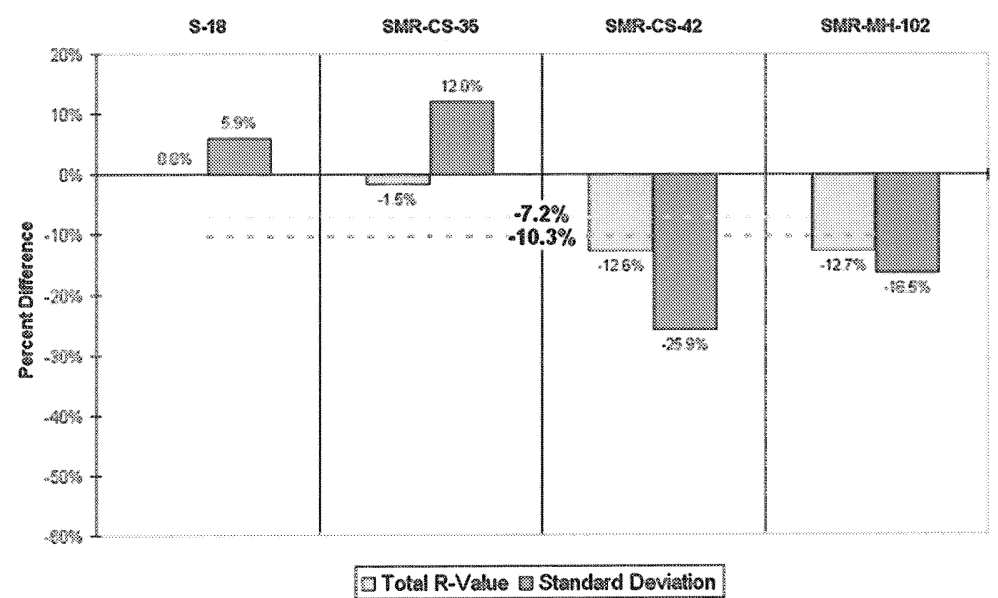

Figure 10.10 R-value comparison: calibrated radar-rainfall vs. IDS weighting of gauges.

\subsection{Conclusions and Lessons Learned}

In the greater Pittsburgh region, the ALCOSAN authority and its 83 tributary service communities have made a significant investment to develop and refine the Regional Long Term Wet Weather Control Plan that is intended to control 
$\mathrm{CSO}$ and SSO discharges into area water bodies. Significant investments were and are still being made to better inventory and characterize regional wastewater conveyance and treatment systems, municipal collection systems, and private service laterals. Complex hydrologic and hydraulic models have been prepared and are in the process of being refined to better quantify and characterize extraneous groundwater and storm water flow in sewer systems and the corresponding frequency and duration of CSO/SSO discharges. Existing precipitation data sources would have limited ALCOSAN to using either the regional long-term gauge record from the airport or a handful of short-term regional gauges scattered over the area. However, in the greater Pittsburgh region, an investment was also made to significantly improve the precision and accuracy of precipitation measurement. It was concluded that the expenditure in developing and implementing a regional calibrated radar-rainfall system was a worthwhile investment that will result in multiple benefits to the region. This conclusion is supported below.

Model computations of the quantity of extraneous flow in sanitary sewer collection systems decreased significantly as a result of improved rainfall measurement. If data from the existing regional long-term gauge were to have been used as the rainfall input to the hydrologic model, extraneous RDII flow in sewer systems would have been significantly over-predicted. The regional investment to obtain improved precipitation measurements resulted in a significant decrease in the computted percentage of rainfall that enters the sewer system. This over-estimate was observed in all of the sewersheds that were analyzed, and the magnitude of the over-estimation was as high as $23 \%$. Similarly, if a nearest gauge approach were to have been used for precipitation data input, the magnitude of over-estimation would still be as high as $13 \%$ to $14 \%$. To put this in perspective, a realistic goal for a typical municipal sewer rehabilitation program is to reduce extraneous RDII flow by approximately $15 \%$ to $30 \%$ Few sewer system rehabilitation programs achieve higher reductions in extraneous flow without extending the rehabilitation program into the private portion of the collection system. For the ALCOSAN program, significant reductions in computed RDII flow were achieved by improving the precision and accuracy of precipitation measurement, before any sewer rehabilitation activities were performed.

The width of the confidence limit bands, representing the level of variability or uncertainty in the analysis results, decreased significantly as a result of improved rainfall measurement. For the level of rainfall data refinement to be commensurate with other variables in the analysis and planning process, the levels of uncertainty should be similar. If rainfall data from the regional 
gauge or a single closest gauge were to have been used as the precipitation input to the hydrologic model, the resulting band width of the $66 \%$ confidence limits (the selected indicator of variability) would have been quite large. Improvements in rainfall measurement reduced the level of variability and uncertainty by as much as $57 \%$ for the regional gauge approach and as much as $49 \%$ for the nearest gauge approach. It is assumed that this improvement is directly attributable to improvements in rainfall measurement and the remaining variation is attributable to other physical parameters impacting $\mathrm{R}$-values (like antecedent moisture and groundwater table levels). Without improvement to precipitation measurement, the variability and uncertainty associated with rainfall would have been significantly larger than the uncertainty associated with modeling, facility sizing, or cost estimation. That is to say that imprecise or nonrepresentative rainfall measurement would have been the "weakest link" in the analysis and design process for the greater Pittsburgh region.

Orographic influences in the Pittsburgh area were found to be significant. If the ALCOSAN service area were flat and rainfall tended to be relatively uniform over the Pittsburgh region, then refinements to precipitation monitoring may not have been needed. However, the terrain within the Pittsburgh area is highly variable and storm fronts tend to be strongly influenced as they pass over the Allegheny Mountain range. The improved resolution of rainfall data provided by the calibrated radar-rainfall system demonstrated that the geographic distribution of storm depths and durations is significant in the greater Pittsburgh region. A more simplified approach to rainfall measurement would have been detrimental to the development of the regional Long Term Control Plan.

It was determined that imprecise or non-representative rainfall could lead to incorrect or misdirected remedial action. It has been estimated that up to two billion dollars may need to be invested in the rehabilitation and reconstruction of municipal collection systems and private service lateral connections to control CSO and SSO discharges and meet the requirements of regulatory agencies. The completed and ongoing physical investigations and modeling analyses are used to estimate the level of effort needed to reduce extraneous flows into the sewer system. The investigations and analyses were also used to prioritize the individual sewersheds in terms of which ones would need higher or lower levels of corrective effort and to determine which sewersheds would be the first to receive corrective action and which ones could be deferred to a later place in the implementation schedule. The Saw Mill Run study showed that improvements in the accuracy and precision of rainfall measurement produced model results that indicated that lower levels of rehabilitation effort were 
required to meet maximum wet weather flow limits. Less precise and accurate rainfall data could have resulted in unnecessary remediation expenditures and increased cost.

Study results were inconclusive regarding the relative value added from a medium-density gauge network versus a calibrated radar-rainfall system. The Saw Mill Run study was able to quantify significant improvements to modeling accuracy when results from model runs using rainfall data from the calibrated radar-rainfall system (using a representative, spatially distributed rainfall over the sewershed) were compared with model run results using precipitation input from either the regional or nearest gauges (using a constant rainfall over the entire sewershed). However, the study results were far less conclusive when model runs were compared using spatially distributed input rainfall data from the medium-density gauge network and data from the calibrated radar-rainfall system. This observation was unexpected since the pixel grid resolution associated with the radar-rainfall systems is much higher than the corresponding density of the gauge network. Significant differences in the modeled quantity of extraneous wet weather flow were observed in half of the sewershed areas that were analyzed. No differences were observed in the other half of the sewersheds. Radar-rainfall data significantly reduced or improved the width of the confidence limit bands, or the level of uncertainty, in half of the analyzed sewershed areas. It is assumed that these improvements are attributable to improved rainfall measurement and that the residual variability is associated with the other physical parameters that impact RDII (such as antecedent moisture and ground water levels). However, in the other half of the analyzed sewersheds, the level of uncertainly actually increased. Additional analyses in other study areas within the ALCOSAN system will show whether or not this trend will continue.

The study shows that improving the precision and accuracy of precipitation measurement is a wise investment and is cost effective. The estimated cost for the ALCOSAN service area to implement the Regional Long Term Wet Weather Control Plan has been estimated to be as high as US\$3 billion. In support of this plan, regional investments are being scheduled and implemented for data collection and facilities design. A regional investment is also being made for precipitation monitoring. The estimated cost for field investigations, field verification and sewer system mapping is approximately US\$60 to $\$ 80$ million. The estimated cost for wastewater flow monitoring is US\$80 to $\$ 100$ million and the cost for facility design has been estimated to be as high as US\$360 to $\$ 450$ million. By comparison, the initial start-up cost to implement the calibrated radar-rainfall system was approximately US $\$ 175,000$ and the total cost to keep 
the system running over a period of 10 years has been estimated to be US\$660,000. It would appear that the cost associated with accurate and precise rainfall measurement is relatively low when compared to the cost of obtaining field-verification and flow-monitoring data. If the overall cost of implementing the regional LTCP were reduced by even $5 \%$ as a result of improved precipitation measurement, there would be a 200 -fold return on the investment. It is therefore concluded that improving the accuracy and resolution of precipitation measurement in the greater Pittsburgh region was a wise investment.

\section{References}

Blanchet, Frederic et al., "Influence of the Spatial Heterogeneity of Precipitation upon the Hydrologic Response of an Urban Watershed", Presented at the Second International Symposium on Hydrological Applications of Weather Radar, University of Hanover, MO, September 7-10, 1992

Curtis, David C.et al., "A Comparison of Radar-Rainfall Estimates and Rain Gauge Observations at Three Different Scales", Presented at the 1996 Association of State Flood Plain Managers Conference, San Diego, CA, June 16, 1996

Curtis, David C., and Rod Thornhill, "Use of Gauge-Adjusted Radar-Rainfall Estimates for Inflow / Infiltration Studies", AMS Conference on Hydrology, Long Beach CA, February 2-7, 1997

Curtis, David C., and Rod Thornhill, "Use of Radar and Rain Gauge Estimates in Inflow / Infiltration Analyses to Improve Remediation Recommendations", presented at the AWRA 34th Annual Conference, Mobile, AL, November 19, 1998

Curtis, David C., "Practical Applications of Gauge Adjusted Radar-Rainfall Estimates", Presented at the ASCE 26th Annual Water Resources Planning \& Management Conferecne, Tempe, AZ, June 6-9, 1999

Jacquet, Guy et al., "Radar-Based Rainfall Input Requirements - Synthesis of 10 Years of US and French Experience", to be presented at the 9th International Conference of Urban Storm Drainage, Portland, OR, September 8-13, 2002

Vieux, B.E., and P.B. Bedient, "Estimation of Rainfall for Flood Prediction from WSR88D Reflectivity: A case Study, American Meteorological Society Journal of Weather and Forecasting, Vol. 13, pp. 126-134, 1998

Vieux, Baxter E., "Radar Rainfall Applications in Hydrology", Chapter 11 in Bedient, P.B., and W.C. Huber, Hydrology and Floodplain Analysis, Addison-Wesley Publishing Co, Reading, MA, 3rd Edition 